\title{
Internacionalizar para quê? \\ As razões de instituições públicas de ensino superior no Ceará
}

\author{
Internationalize for what? \\ The rationales for public institutions of higher education in Ceará
}

\author{
Linnik Israel Lima Teixeira ${ }^{1}$ \\ Maria Elias Soares ${ }^{2}$ \\ Marcos Antônio Cavalcante de Oliveira Júnior ${ }^{3}$ \\ Elane dos Santos Silva Barroso ${ }^{4}$ \\ Maria do Socorro de Sousa Rodrigues ${ }^{5}$
}

Resumo: A internacionalização do ensino superior ganhou grande repercussão nas universidades brasileiras, que passam a ter cada vez mais inserção no cenário científico e acadêmico internacional, evidenciada pelos rankings elaborados por organismos internacionais. Dado que a internacionalização vem sendo gradativamente institucionalizada nas universidades, no âmbito do planejamento e da estrutura organizacional, o presente estudo busca compreender as razões que as motivam a participar do processo. Entender as razões contribui no estabelecimento de políticas específicas para o tema, visto que é etapa inicial para o planejamento. Classificado como uma pesquisa descritiva, com abordagem qualitativa, o estudo delimitou três instituições federais de ensino superior (IFES) no Ceará com ações reconhecidas de internacionalização. $\mathrm{Na}$ pesquisa de campo, realizaram-se entrevistas com gestores das IFES envolvidos no fenômeno, e na pesquisa documental coletaram-se dados sobre o histórico de atuação das IFES na internacionalização. Os resultados evidenciam que as principais razões consistem em: capacitação docente, capacitação discente nas dimensões profissional e cultural, busca por reputação e reconhecimento e pressões ambientais. As diferenças entre as IFES podem ser explicadas pela sua história e missão institucional. Os resultados são convergentes com a literatura e contribuem como diretrizes na elaboração do planejamento de políticas institucionais para internacionalização.

Palavras-chave: Internacionalização. Instituições de ensino superior. 
Abstract: The internationalization of higher education has gained significant repercussions in Brazilian universities, which are increasingly inserted in the international scientific and academic scene, evidenced by the rankings prepared by international organizations. Given that internationalization has been gradually institutionalized in universities, within the scope of planning and organizational structure, this study seeks to understand the rationales that motivate them to participate in the process. Understanding the rationale for internationalization contributes to establishing specific policies for the theme since it is an initial stage for planning. Classified as a descriptive research, with a qualitative approach, the study delimited three federal higher education institutions (IFES) in Ceará with recognized internationalization actions. In the field research, interviews were conducted with IFES managers involved in the phenomenon, and in the documentary research, data were collected on the history of IFES 'performance in internationalization. The results show that the main rationales are: teacher training, student training in the professional and cultural dimensions, search for reputation and, recognition and environmental pressures. Their institutional history and mission can explain the differences between IFES. The results are convergent with the literature and contribute the guidelines in the preparation of institutional policy planning for internationalization.

Keywords: Internationalization. Higher education institutions.

\author{
${ }^{1}$ Instituto Federal do Piauí | Piripiri | PI | Brasil. \\ Contato: linnik.lima@gmail.com. ORCID: https://orcid.org/0000-0002-5973-5373 \\ ${ }^{2}$ Universidade Federal do Ceará | Programa de Pós-Graduação em Políticas Públicas e \\ Gestão da Educação Superior | Fortaleza | CE | Brasil. \\ Contato: melias@ufc.br. ORCID: https://orcid.org/0000-0003-3747-1941 \\ ${ }^{3}$ Instituto Federal do Piauí | Piripiri | PI | Brasil. \\ Contato: marcos.cavalcante@ifpi.edu.br. ORCID: https://orcid.org/0000-0003-0630-4913 \\ ${ }^{4}$ Instituto Federal do Piauí | Piripiri | PI | Brasil. \\ Contato: elane.silva@ifpi.edu.br. ORCID: https://orcid.org/0000-0002-3055-3840 \\ ${ }^{5}$ Universidade Federal do Ceará| Programa de Pós-Graduação em Políticas Públicas e \\ Gestão da Educação Superior | Fortaleza| CE | Brasil. \\ Contato: sspaliti2@gmail.com. ORCID: https://orcid.org/0000-0002-0656-7708
}

- Recebido em: 8 de junho de 2020

- Aprovado em: 23 de maio de 2021

DOI: http://dx.doi.org/10.1590/S1414-40772021000300009

Este é um artigo publicado em acesso aberto sob uma licença Creative Commons https://creativecommons.org/licenses/by-nc/4.0/ 


\section{Introdução}

As consequências do sistema globalizado têm gerado oportunidades e desafios às instituições de ensino superior (IES). Pode-se destacar o intercâmbio de experiências e acordos de pesquisa. Como desafio, a competitividade atual gera às IES a necessidade de contínua adaptação às mudanças promovidas pela globalização, pois é nesse cenário que ocorre a disseminação do conhecimento e incentivos ao desenvolvimento de estudos e descobertas científicas. Ademais, Altbach (2004, p. 4) alerta que "a globalização não pode ser completamente evitada. A história mostra que, quando universidades se fecham para as tendências econômicas e societais, elas se tornam moribundas e irrelevantes".

Não obstante, a globalização tem não só oportunizado como também é uma razão para as IES aderirem à internacionalização. Gao, Baik e Arkouds (2015) afirmam que as razões para a internacionalização universitária modificaram-se ao longo das décadas em função do contexto histórico envolvido, e a globalização reflete-se no atual momento. Segundo Knight (2004), as instituições precisam definir suas razões para internacionalização de modo a tornar evidentes que benefícios são aguardados e que esforços precisam ser realizados. Além disso, a definição das razões possibilita compreender como ocorre o processo de internacionalização de uma determinada IES.

Diversos estudos teóricos sistematizam as razões para internacionalização (DE WIT, 2002; ALTABCH; KNIGHT, 2007; KNIGHT, 2012; WADWHA, 2016). Por sua vez, estudos empíricos desenvolvidos na Europa mostram que a busca por prestígio, competição por fontes de recursos e aperfeiçoamento do ensino são proeminentes razões para a internacionalização das IES (DE WIT; ADAMS, 2010; SEEBER et al., 2016; SEEBER; MEOLI; CATTANEO, 2018). As universidades europeias e americanas despontam como destaques na internacionalização de suas atividades perante outros países, por meio de prestação de serviços educacionais, cursos a distância e programas de intercâmbio estudantil consolidados. Os principais resultados advindos dessas atividades são o incremento de receitas e o fortalecimento de parcerias institucionais (HUDSON, 2016).

No Brasil, pesquisas empíricas sobre internacionalização do ensino superior concentram-se em estudos de caso, abordando o processo de internacionalização de IES ou de áreas de conhecimento (MIURA, 2006; BATISTA, 2009; BEZERRA, 2012; LAUS, 2012; VILALTA, 2012; CHRISTINO, 2013; MUELLER, 2013; OLIVEIRA, 2018). Tendo em vista o contexto heterogêneo do ensino superior brasileiro, estudos empíricos, sobretudo regionalizados, são necessários. 
Considerando que as razões da internacionalização são o ponto inicial do processo e que elas moldam as ações desenvolvidas pelas IES (KNIGHT, 2004), este trabalho teve como objetivo investigar as razões que levaram três instituições federais de ensino superior (IFES) do Ceará a se internacionalizarem. A escolha das instituições justifica-se por estarem situadas no mesmo âmbito federativo, que possibilita uma melhor análise de suas semelhanças e diferenças.

Este trabalho está dividido em cinco capítulos. O primeiro é a apresentação da pesquisa, o segundo capítulo deste artigo vai tratar da internacionalização no ensino superior e as razões das instituições para internacionalizar. O capítulo três traz a descrição da metodologia, o quarto capítulo discorre sobre os resultados e discussões e o quinto contém as considerações finais e sugestão de trabalhos futuros.

\section{Internacionalização no ensino superior}

Internacionalização é definida "no nível nacional, setorial e institucional como o processo de integração de uma dimensão internacional, intercultural ou global nos objetivos, funções ou serviços na educação superior” (KNIGHT, 2003, p. 2). A globalização é um processo que exerce impacto sobre a internacionalização, em outras palavras, "a internacionalização está mudando o mundo da educação e a globalização está mudando o mundo da internacionalização" (KNIGHT, 2003, p. 3).

Sobre a definição anterior, é importante destacar que os termos utilizados foram escolhidos cuidadosamente. Knight (2005) explica que se trata de uma definição neutra. Embora alguns argumentem que uma definição de internacionalização devesse incluir questões como a promoção da integração e da solidariedade entre nações, aumento da qualidade do ensino superior ou a contribuição das pesquisas na resolução de problemas internacionais, a autora defende que uma definição necessita neutralidade, pois porque se trata de um fenômeno que, embora universal, tem propósitos e resultados em diferentes lugares, dependendo dos atores ou stakeholders envolvidos.

Não obstante a essa heterogeneidade, De Wit (2019) apresenta características comuns às iniciativas de internacionalização surgidas nas últimas décadas: foco na internacionalização no sentido país-exterior em vez de exterior-país; processos fragmentados, sem políticas centralizadas; foco em razões econômicas; pouco alinhamento entre ensino, pesquisa e serviços; pouca importância aos países em desenvolvimento.

De acordo com Miura (2006), a discussão sobre a importância da internacionalização no ensino superior ganhou importância a partir da década de 1980, motivada por várias razões: 
exigências profissionais e acadêmicas para os graduados, refletidas nas demandas de mercado; esforço de colaboração e intensa cooperação para potencializar o nível de especialização da pesquisa; e o recrutamento de estudantes estrangeiros para incrementar as receitas das instituições.

Teichler (2009), por sua vez, comenta que, na Europa, o debate sobre a internacionalização também inclui a expectativa de ela ser um instrumento de paz e entendimento entre os países, promovendo a riqueza cultural e o desenvolvimento humano. Teichler (2009) afirma que, na Europa, a internacionalização no ensino superior já faz parte da agenda dessas instituições, influenciada principalmente pelo Processo de Bolonha, que, segundo Morgado (2009), constituiu um marco na educação europeia por meio da criação de um espaço que promovesse a mobilidade de alunos e docentes, desenvolvimento econômico e social europeu e aumento da competitividade com outros sistemas do mundo, especialmente Estados Unidos e Japão. Na América Latina, Berry e Taylor (2014) observam que a internacionalização é pouco desenvolvida, justificada, em muitas situações, pelos custos e entraves nacionais e institucionais. No entanto, Berry e Taylor (2014), ao investigar a internacionalização em universidades na Colômbia e no México, descobriram que essas universidades já incluem a internacionalização nas suas agendas e que há uma preocupação em formar estudantes com visão do mundo. Ainda assim, os autores destacam que a falta de um planejamento estratégico sobre o tema as tornam distantes dos modelos desenvolvidos na Europa, Estados Unidos e Japão.

Face à heterogeneidade de cenários nacionais, regionais e setoriais, certamente as motivações para adotar ou não processo de internacionalização variam entre as instituições de ensino. O próximo tópico destaca as principais razões para internacionalização universitária.

\subsection{Razões para Internacionalização de IES}

O crescimento das discussões sobre internacionalização no ambiente das IES naturalmente resulta no interesse estratégico de conhecer por quais razões este fenômeno tem tido grande notoriedade. Para Miura (2006), pesquisar sobre as razões é perguntar por que governo, órgãos internacionais, setor privado e instituições de ensino superior estão envolvidas com o fenômeno da internacionalização. Miura (2006) também esclarece que as classificações variam entre autores, mas essas classificações acabam por se sobrepor umas às outras. Ademais, as razões para internacionalização apontadas na literatura apresentam relativa estabilidade ao longo das décadas, ou seja, sem mudanças significativas. A despeito da mudança de cenário 
global ao longo das décadas e de novos cenários de internacionalização, quando investigadas as razões, essas se relacionam em sua essência a razões já indicadas na literatura.

Por outro lado, a perspectiva de classificação das razões para internacionalização tem variância entre os autores ao longo dos anos, revelando-se uma forma interessante de explanação. Em vista disso, optou-se, no referencial teórico, por uma abordagem cronológica das razões, evidenciando a visão dos pesquisadores.

Aigner, Nelson e Stimpfl (1992) apontaram três grandes razões para a internacionalização do ensino superior: o interesse na segurança nacional; manutenção da competitividade econômica; e a busca pelo entendimento humano mútuo entre os países.

Scott (1992) identificou sete razões para o alcance da educação internacionalizada: competitividade econômica; interdependência ambiental; crescimento da diversidade étnica e religiosa nas comunidades locais; empresas internacionais atuando em âmbito local; influência de grandes corporações internacionais em pequenos negócios locais; diversidade étnica no mercado de trabalho; e segurança nacional e paz entre as nações.

Já Warner (1992) refletiu sobre a diversidade de razões de acordo com a agenda de cada universidade. Em resultado, estabelecem-se três modelos para explicar as motivações institucionais para internacionalização: o modelo competitivo, em que as instituições direcionam seus currículos e outras atividades para tornar estudantes e professores competitivos no mercado econômico global; o modelo liberal, que identifica os objetivos principais da internacionalização como um autodesenvolvimento em um ambiente de mudança global; o modelo de transformação social, que prega que o mais importante é conferir aos estudantes uma consciência profunda das questões internacionais e interculturais relacionadas à igualdade e justiça e fornecedor ferramentas para atuarem criticamente e ativamente em direção à transformação social.

Não obstante essas classificações, De Wit e Knight foram os primeiros a dividir as razões em políticas, culturais, acadêmicas e econômicas. Essa classificação influenciou autores posteriores.

De Wit (2002) dividiu em quatro categorias as razões que levam as organizações a adotarem a internacionalização: a primeira razão é de ordem política, que engloba os aspectos de segurança nacional, paz e acordos internacionais. De Wit (2002) apontou também as razões econômicas para a internacionalização. $\mathrm{O}$ autor observou o crescimento das razões econômicas e sua sobreposição a outras razões, inclusive políticas. Isso acontece na Áustria, Alemanha, Holanda, Reino Unido e países da região escandinava (DE WIT, 2000). A terceira razão mencionada pelo autor é de ordem social/cultural. Segundo De Wit (2002), a razão cultural tem 
a ver com papel da universidade, por meio do ensino e pesquisa, em atuar no desenvolvimento de competências interculturais em seus estudantes. No social, relaciona-se em transformar os estudantes e pesquisadores em indivíduos preparados para atuarem no ambiente internacional. A última motivação são os fatores acadêmicos: desenvolvimento de uma dimensão internacional no ensino e na pesquisa, resultando no aperfeiçoamento e crescimento da instituição aos moldes dos padrões internacionais, garantindo sua visibilidade e reputação e aumento de prestígio em rankings internacionais (DE WIT, 2002).

Knight (2004) rebateu a classificação dada por De Wit (2002), visto que, segundo a autora, as razões supracitadas são genéricas, pois abrangem tanto o nível nacional (Top-Down) como o institucional (Bottom-Up). Assim, Knight (2004) defendeu classificar as razões da internacionalização em cada um dos níveis citados. No nível nacional, as razões são: a) desenvolvimento de recursos humanos; b) alianças estratégicas; c) transações comerciais; d) desenvolvimento cultural e social; e) construção da nação.

Knight (2004) ressaltou que, embora as razões institucionais e nacionais possuam estreita ligação, na prática tais relações não são tão próximas quando deveriam, visto que dependem de uma relação de muitos fatores, tais como o quanto a internacionalização ocorre numa perspectiva Top-Down ou Bottom-Up. A realidade indica que, quando o nível nacional não é proeminente, o nível institucional ganha maior destaque, resultando em maior heterogeneidade de processos de uma instituição para outra.

No nível institucional, há muitos fatores que influenciam as razões da internacionalização, que abrangem a missão, o perfil dos estudantes, o perfil da instituição, a localização geográfica, fontes de financiamento e interesses em regiões específicas. As seguintes razões: a) perfil institucional e reputação; b) desenvolvimento de estudantes e professores; c) geração de receitas; d) alianças estratégicas; e) pesquisa e produção de conhecimento.

Perfil institucional e reputação relacionam-se com o reconhecimento e prestígio no ambiente ao qual está inserido, o que aumenta a capacidade de atrair bons estudantes e professores, como também enviar seus estudantes e professores a outras instituições com boa reputação. Conquanto, Knight (2004) observa criticamente que a busca de atingir bons padrões de ensino e pesquisa são apenas um meio para conseguir bons índices de competitividade local, nacional e internacionalmente.

A internacionalização também pode contribuir para desenvolver estudantes e professores para compreenderem e lidarem com as complexas questões internacionais, nacionais, regionais e culturais que aumentaram vertiginosamente nos últimos anos. A 
habilidade em lidar com múltiplas culturas e ambientes é essencial em um mercado de trabalho globalizado. Adicionalmente, as tecnologias de informação disponíveis facilitam conhecer o mundo de forma mais profunda, que viabiliza maior número de oportunidades profissionais. Ao mesmo tempo, as competências que estudantes e professores desenvolvem durante iniciativas de internacionalização são importantes em meio à ênfase atual dada a educação baseada em entrega de resultados à sociedade.

A geração de receitas refere-se à motivação econômica para internacionalizar, porém Knight (2004) alerta que o uso das receitas geradas é frequentemente questionado quanto à sua destinação e quanto à motivação, ou seja, se o objetivo é de fato cobrir custos ou simplesmente lucrativa. Muitos defendem que esse assunto é uma decisão institucional, outros argumentam que os ganhos obtidos devem ser reinvestidos em projetos de internacionalização, sob o risco de transformá-la em mais um tipo de comoditização da educação.

As Alianças Estratégicas são as parcerias estratégicas com instituições relevantes, com objetivos científicos, humanos, culturais ou tecnológicos. Instituições experientes estabelecem parcerias com foco estratégico e com objetivos bem definidos, e levam em conta as diferenças culturais e as especificidades na forma de trabalhar de outras instituições (KNIGHT, 2004).

A pesquisa e produção de conhecimento são fatores centrais no modelo de ensino superior. Com a interdependência entre as nações, os desafios excedem o âmbito nacional e tornam-se preocupação global. A complexidade das questões exige discussões interdisciplinares para solucionar problemas que ameacem o ambiente, a saúde e a segurança mundial. Nesse contexto, o caráter interdisciplinar e científico das universidades o torna peça central dessas discussões, oferecendo-as o estímulo (ou desafio) para que integrem a dimensão internacional em suas atividades de produção de conhecimento e avanço da ciência.

\section{Método}

A pesquisa tem uma abordagem qualitativa (DENZIN; LINCOLN, 2003). Os dados foram coletados entre por meio de análise documental e realização de entrevistas. As entrevistas executadas nesta pesquisa tiveram como referência o roteiro desenvolvido e validado por Miura (2006), com a finalidade de coletar as percepções dos atores da Administração Superior envolvidos diretamente ou indiretamente no processo de internacionalização das IFES. Além da pesquisa de campo, o estudo utiliza pesquisa documental com o objetivo de coletar os principais dados referentes à história das instituições, especialmente no tocante às ações de internacionalização ou outras atividades que indiretamente contribuam para o fenômeno. 
As unidades de análise para o estudo, como já explanado, são as IFES do Ceará: a Universidade Federal do Ceará, o Instituto Federal de Educação Ciência e Tecnologia do Ceará e a Universidade da Integração Internacional da Lusofonia Afro-Brasileira. A pesquisa consiste na investigação da internacionalização no nível institucional das instituições pesquisadas.

É importante registrar que o Ceará possui atualmente 4 IFES. A Universidade Federal do Cariri (UFCA), quarta IFES existente, foi criada em 2013 a partir de um desmembramento da Universidade Federal do Ceará, mantendo-se um acordo de Cooperação Técnica (UFCA, 2018). Neste estudo, a instituição não foi incluída entre as estudadas, justificado pela questão do acesso e pelo recente processo de desmembramento da UFC.

Foram entrevistados os gestores administrativos de modo a compreender as políticas e estratégias da UFC, IFCE e UNILAB quanto ao tema. Estão compreendidos nessa abordagem. Na UFC: Reitor, Pró-Reitor de Pesquisa e Pós-Graduação, Pró-Reitor de Relações Internacionais, Pró-Reitor de Graduação, Pró-Reitora de Extensão e Coordenadores de PósGraduação (Física, Matemática, Recursos Hídricos, Farmacologia, Ciências Médicas). No IFCE: Reitor, Assessor de Relações Internacionais, Pró-Reitor de Pesquisa, Pós-Graduação e Inovação e Pró-Reitora de Ensino. Na UNILAB: Reitor, Pró-Reitor de Relações Institucionais, Pró-Reitora de Pesquisa e Pós-Graduação, Pró-Reitora de Graduação e Pró-Reitora de Extensão, Arte e Cultura.

Apenas a UFC possui coordenadores de pós-graduação com cursos de inserção internacional, que são aqueles com Conceito CAPES 6 ou 7 na última avaliação feita pela Coordenação de Aperfeiçoamento de Pessoal de Nível Superior (CAPES), avaliação que as inserem no contexto de reconhecimento internacional.

As entrevistas foram realizadas no período de 20 de junho a 14 de julho de 2018 e aconteceram no próprio ambiente de trabalho dos pesquisados e totalizaram 20 horas. Na seção de Resultados e discussões, foi atribuída de forma aleatória uma letra do alfabeto para cada entrevistado, de modo a preservar o anonimato.

A pesquisa de campo utilizou a entrevista padronizada aberta (GODOI; MATTOS, 2006), pois dessa forma há certo grau de estruturação, posto que o entrevistador tenha pontos de interesse que irá explorar ao longo da conversa. Dado que o objetivo do trabalho é investigar o processo de internacionalização das IFES a partir de pontos específicos e a partir da realidade vivida por cada entrevistado, esse tipo de entrevista revela-se como a mais adequada. 


\section{Resultados e discussões}

Esta seção divide-se em dois tópicos: o primeiro corresponde à apresentação e histórico de ações de internacionalização das instituições, provenientes de análise documental; o segundo consiste na análise das entrevistas com os atores organizacionais descritos anteriormente.

\subsection{Histórico e ações das instituições}

\section{Universidade Federal do Ceará (UFC)}

A Universidade Federal do Ceará foi criada em 1954, e atualmente, conta com 118 cursos presenciais de graduação, 9 cursos de graduação na modalidade de Educação a Distância (EAD), 71 cursos de mestrado e 45 cursos de Doutorado (UFC, 2017).

A UFC conserva um histórico de ações na área de internacionalização. Na década de 1960, surgiu o que seria um dos maiores programas de extensão na área de internacionalização: os Centros de Cultura Estrangeira, atualmente denominadas Casas de Cultura Estrangeira. Sob a direção do Centro de Humanidades e da Pró-Reitoria de Extensão, as Casas de Cultura Estrangeiras são compostas pela Casa de Cultura Hispânica (1961), Alemã (1962), Italiana (1963), Britânica (1964), Portuguesa (1964), Esperanto (1965) e Francesa (1967) (UFC, 2018a). Em 2014, a UFC fechou parceria com o Instituto Confúncio para a instalação de uma unidade na UFC. O Instituto Confúncio é um órgão vinculado ao Ministério da Educação Chinesa e tem como objetivo promover a internacionalização da língua chinesa. (NEZ, 2019).

Em 1957, três anos após sua fundação, já contava com uma Divisão de Intercâmbio e Expansão Cultural (UFC, 2018b), evoluindo para Comissão de Assuntos Internacionais em 1974, depois Coordenadoria de Assuntos Internacionais em 1987 e, por fim, sendo elevada a Pró-Reitoria de Relações Internacionais (PROINTER) em 2017. A PROINTER subdivide-se em 3 coordenadorias: Coordenadoria de Mobilidade Acadêmica, Coordenadoria de Intercâmbio e Convênios Internacionais e Coordenadoria de Internacionalização Linguística.

A UFC, por meio da PROINTER, detém acordos e convênios internacionais vigentes em universidades de todos os continentes: América (Argentina, Canadá, Chile, Colômbia, Estados Unidos, México e Peru), África (Cabo Verde e Marrocos), Ásia (China e Paquistão) Europa (Alemanha, Bélgica, Espanha, França, Itália, Países Baixos, Portugal, Reino Unido, Suécia e Suíça), Oceania (Austrália), totalizando 22 países (UFC, 2018c).

$\mathrm{Na}$ área de pós-graduação, a UFC destaca-se em dez programas com inserção internacional, de acordo com a última avaliação feita pela CAPES. São ao todo 10 cursos de pós-graduação da UFC com reconhecimento internacional: Engenharia Civil em Recursos 
Hídricos, Física e Matemática (Conceito 7), Ciências Médicas, Farmacologia, Geografia, Enfermagem, Engenharia de Teleinformática, Engenharia Química e Química (Conceito 6).

É importante ressaltar que a maioria desses cursos existe há décadas e possuem ações próprias de internacionalização antes mesmo de haver políticas institucionais de incentivo. Em vista disso, diversas ações dessa natureza não constam em registros oficiais da universidade na área de pesquisa, a produção intelectual da UFC atingiu no ano de 2016 o número de 1.827 publicações em periódicos indexados, sendo 467 (26\%) nos estratos A1 ou A2 (UFC, 2017).

\section{Instituto de Educação, Ciência e Tecnologia do Ceará (IFCE)}

O Instituto de Educação, Ciência e Tecnologia do Ceará surgiu em 1909, por meio do Decreto $\mathrm{n}^{\circ}$ 7.566, que criou a Escola de Aprendizes Artífices. Em 1941, foi denominada de Liceu Industrial do Ceará. Em 1968, passou a chamar de Escola Técnica Federal do Ceará. Em 1994, recebeu o nome de Centro Federal de Educação Tecnológica, momento em que foi autorizada a oferecer cursos de nível superior, além de atividades de pesquisa e extensão. Em 2008, transformou-se em Instituto Federal (IFCE, 2015). Portanto, mais de 8 décadas a instituição atuou somente no nível da educação básica e profisssional.

São oferecidos 82 cursos técnicos nas modalidades concomitante, subsequente e integrado (nível médio). No âmbito do ensino superior, são oferecidos 17 bacharelados, 13 licenciaturas e 20 tecnólogos. Na pós-graduação, o IFCE apresente 7 mestrados próprios e 3 mestrados em rede. $\mathrm{O}$ instituto ainda não oferece cursos de doutorado, compreendido por sua entrada recente na educação superior (IFCE, 2015).

A responsabilidade pela área de internacionalização é atribuída à Assessoria de Relações Internacionais (ARINTER), vinculada diretamente à Reitoria, composta até o momento por dois servidores, que são o próprio Assessor de Relações Internacionais (docente) e um por servidor técnico-administrativo. O objetivo da ARINTER é estabelecer convênios, parcerias, acordos de cooperação e intercâmbio com instituições de ensino, pesquisa, extensão e fomento dos mais diversos países (IFCE, 2018).

A ARINTER também é responsável mediar o relacionamento entre o IFCE e outras instituições parceiras. A instituição mantém parcerias com universidades na América (Argentina, Canadá, Estados Unidos e Guiana), África (Cabo Verde), Ásia (Israel), Europa (Alemanha, França, Itália e Portugal). Sua intermediação inclui a participação como representante do IFCE na Associação de Assessorias de Instituições de Ensino Superior Brasileiras para Assuntos Internacionais e no Fórum de Relações Internacionais dos Institutos Federais de Educação Profissional e Tecnológica. Outra atuação é na gestão de programas com 
caráter internacional, como Programa de Líderes Emergentes das Américas (ELAP), parceria com o governo canadense, Programa Jovens Embaixadores, Programa Ciência Sem Fronteiras e o Programa Estudante-Convênio de Graduação. A instituição conta com o IFCE Internacional, programa próprio de mobilidade acadêmica, que tem se destacado como uma das suas principais ações de internacionalização.

Em mobilidade acadêmica out (envio de estudantes), o IFCE registrou a quantidade indicada no Quadro 1.

Quadro 1 - Número de discentes e docentes enviados ao exterior

\begin{tabular}{|c|c|c|c|c|}
\hline CATEGORIA & 2013 & 2014 & 2015 & 2016 \\
\hline DISCENTE & 46 & 33 & 26 & 17 \\
\hline DOCENTE & 9 & 8 & 10 & 52 \\
\hline
\end{tabular}

Fonte: IFCE - INSTITUTO FEDERAL DO CEARÁ. Pró Reitoria de Administração e Planejamento. Anuário Estatístico 2017 Ano Base 2016. Fortaleza: IFCE, 2017.

$\mathrm{Na}$ área de pesquisa, foram publicados 77 trabalhos em periódicos internacionais, correspondendo a 17,7\% de todas as produções realizadas pelo IFCE. O índice é ligeiramente inferior ao dos anos de 2012 a 2016 (18,5\%, 21,4\%, 22,6\% e 20,2\%) (IFCE, 2017).

\section{Universidade da Integração Internacional da Lusofonia Afro-Brasileira (UNILAB)}

A Universidade da Integração Internacional da Lusofonia Afro-Brasileira foi criada em 2010 e instalada em 2011 na cidade de Redenção, no Ceará. Além dessa cidade, a UNILAB possui um campus na cidade vizinha, Acarape, e em São Francisco do Conde (Bahia). Sua atuação específica é no fortalecimento da integração entre o Brasil e os demais países membros da Comunidade dos Países de Língua Portuguesa (CPLP), em especial os países africanos.

A criação da UNILAB fez parte de uma estratégia de ingresso na comunidade lusófona com a criação de centros de formação e de produção de pesquisa e o fomento à cooperação SulSul, cenários anteriormente não priorizados. Por isso, um de seus princípios basilares é a cooperação solidária (UNILAB, 2013). Assim, a UNILAB busca construir uma ponte histórica entre o Brasil e os países de Língua Portuguesa, especialmente africanos, compartilhando soluções inovadoras para processos históricos similares. Não por acaso, a cidade sede da UNILAB foi a primeira do Brasil a abolir a escravidão. 
A UNILAB tem 8 unidades acadêmicas em diversas áreas de conhecimento: Instituto de Ciências da Saúde, Instituto de Ciências Exatas e da Natureza, Instituto de Ciências Sociais e Aplicadas, Instituto de Desenvolvimento Rural, Instituto de Engenharias e Desenvolvimento Sustentável, Instituto de Linguagens e Literatura, Instituto de Humanidades e Letras do Campus do Malês e Instituto de Educação a Distância (UNILAB, 2018a). As unidades acadêmicas oferecem 16 cursos de graduações presenciais e 1 curso de graduação a distância. No âmbito da pós-graduação, são ofertados 4 cursos de mestrado da própria instituição e 1 mestrado em rede, além de 8 especializações. Ao todo, são 6.733 estudantes. Na graduação presencial, são 3.174 brasileiros e 1.103 estrangeiros. Na pós-graduação, os estudantes totalizam 126 . Na educação a distância, são 696 estudantes em cursos de graduação e 1.634 em cursos de especialização (UNILAB, 2018b).

Na área de internacionalização, a Pró-Reitoria de Relações Internacionais (PROINST) é o órgão específico que trata de assuntos dessa área. No entanto, conforme será comprovado mais a frente, todas as pró-reitorias atuam transversalmente na temática de internacionalização. Além da própria internacionalização, a PROINST atua no cenário local junto aos órgãos e instituições do Maciço de Baturité (Ceará) e São Francisco do Conde (Bahia).

A PROINST atua representando a UNILAB na Rede de Instituições de Públicas de Educação Superior (RIPES), na Associação das Universidades de Língua Portuguesa e na Comunidade dos Países de Língua Portuguesa (CPLP). O órgão mantém convênio com universidades na Angola, Cabo Verde, Guiné Bissau, Moçambique, São Tomé e Príncipe e Timor Leste. Esses mesmos países são a origem dos estudantes que estudam na UNILAB. São 663 estudantes da Guiné Bissau, 227 da Angola, 78 do Cabo Verde, 71 de São Tomé e Príncipe, 38 de Moçambique e 25 do Timor Leste. A maior parte estuda nos cursos de Humanidades (140) e Engenharia de Energias (140) (UNILAB, 2018c).

A PROINST é dividida em três núcleos: Núcleo de Mobilidade e Cooperação Solidária, Núcleo de Projetos Internacionais e Núcleo de Cooperação Internacional (UNILAB, 2018d).

\subsection{Razões para Internacionalização}

Nas seções anteriores foram apontadas diversas razões que podem levar uma IES a se internacionalizar. No âmbito da UFC, os entrevistados indicaram diversas razões. Os trechos das entrevistas citadas nesta seção estão postas ipsis litteris à fala dos entrevistados.

Segundo os entrevistados, a experiência promovida pela internacionalização capacita docentes e discentes. Um ponto importante é o direcionamento que os participantes dão ao 
termo "capacitação". Um dos direcionamentos pode ser dado à capacitação cultural e cidadã, conforme pode ser observado no trecho do entrevistado " $F$ ":

\begin{abstract}
O estudante que tem experiência no exterior, a gente sabe que ele se torna em pouco uma pessoa que tem uma percepção cultural, acadêmica muito mais ampla e muito mais interessante. Isso atinge diretamente a capacitação e a formação dos nossos estudantes e dos nossos docentes, também se internacionalizando, se capacitando mais a passar esse conhecimento e essa percepção global das coisas acadêmica, científica e cultura (ENTREVISTADO F, 2018).
\end{abstract}

Um segundo tipo de capacitação evidenciado é o na pesquisa científica, que viabiliza a inserção de docentes em grupos internacionais e fortalece os grupos de pesquisa da universidade. Umas das consequências desse processo é aumento da competitividade da instituição. A fala do entrevistado "M" explicita os pontos citados:
A primeira certamente está relacionada com a qualificação do corpo docente. Sem uma qualificação apropriada e em nível internacional do nosso corpo docente, você realmente teria dificuldades em ampliar essa participação. Outro fator que realmente é muito importante é a qualidade de alguns grupos de pesquisa que a universidade tem, que não deixam a desejar comparando com nenhum grupo em nível internacional (ENTREVISTADO M, 2018).

As pressões institucionais exercem influência positiva para o processo de internacionalização, que, aliadas à competitividade da UFC, tornam a de internacionalização um processo inevitável. A respeito das pressões institucionais, o entrevistado "I" menciona a CAPES, que atua como indutora no âmbito da pós-graduação:

Primeiro, é uma demanda da Capes, uma demanda da Capes dos programas de pós-graduação. A UFC quer ser reconhecida, quer permanecer como uma universidade de referência e para isso precisa internacionalizar. Basicamente é um caminho sem volta a internacionalização. As universidades que vão conseguir se internacionalizar, vão ter sucesso e as que não fizerem vão ficar fadadas a meras instituições de terceiro grau (ENTREVISTADO I, 2018).

O Programa Ciência sem Fronteiras é um exemplo de programa indutor da internacionalização na dimensão da mobilidade acadêmica. Na primeira metade de 2010, o programa contou com massiva participação das universidades federais, especialmente nos cursos de ciências e tecnologias.

Outros motivos citados, embora em menor frequência, relacionam-se à importância da universalização do conhecimento e ao fortalecimento do ensino.

As razões mencionadas pelos entrevistados se apoiam na terceira razão para internacionalização apontada por De Wit (2002), quando o autor explica a razão de ordem social/cultural. Do ponto de vista cultural, a universidade tem o papel de, por meio do ensino e pesquisa, atuar no desenvolvimento de competências interculturais em seus estudantes. No social, relaciona-se em transformar os estudantes e pesquisadores em indivíduos preparadas para atuarem no ambiente internacional. No entanto, os entrevistados não identificaram a 
importância da internacionalização em construir relações pacíficas entre diferentes povos, limitando-se ao engrandecimento como indivíduo.

Outra razão bastante recorrente é a busca pela competitividade e prestígio no meio acadêmico. Knight (2004) esclarece que, dentre as razões institucionais para internacionalização, o perfil institucional e reputação é um dos mais procurados pelas universidades, visto que isso implica em maior atração de estudantes e estrangeiros e também a possibilidade de maior recurso financeiro pelas instituições de fomento. Knight (2004) indica adicionalmente a formação de alianças estratégicas com fins científicos, tecnológicos, humanos ou de pesquisa. Essa se constitui de outra forte razão para a internacionalização, principalmente pela constatação de que a UFC estabelece parcerias principalmente com os países que se encontram na ponta tecnológica.

No IFCE, as razões indicadas pelos entrevistados foram diversas. A capacitação de servidores (professores e técnico-administrativos) e estudantes foi um dos pontos mais destacados, sobretudo no tocante à mobilidade acadêmica. Na dimensão estudantil, a percepção cultural é bastante destacada.

[...] o crescimento profissional, a maturidade dos alunos. E até assim a formação integral desse aluno que nós temos aqui [...] A cultura que ele tem lá fora é diferente da nossa. E a troca quando ele chega aqui, que ele passa a ver que a nossa instituição... Ele começa a comparar o que nós temos aqui com o que ele tinha lá fora. Então são coisas que a instituição tem que realmente investir (ENTREVISTADO C, 2018).

Ao contrário dos entrevistados da UFC, os participantes do IFCE assinalam capacitação docente e técnico-administrativa dentro de um mesmo processo. Se na UFC o foco maior é a pesquisa, no IFCE destaca-se a busca por titulações superiores. O entrevistado "A” menciona o crescente o número de servidores (docentes e técnicos) que consegue oportunidades para estudar no exterior.

A busca de reconhecimento externo é outro fator destacado nas entrevistas. Para os entrevistados, a internacionalização é umas das oportunidades que a instituição tem para se igualar à atuação das universidades. Nesse aspecto, os entrevistados "B" e "D" apontam a pesquisa e pós-graduação como o caminho para esse objetivo. Se antes a instituição atuava apenas como escola técnica profissionalizante, hoje tem a oportunidade de dialogar com grandes pesquisadores. Para o entrevistado " $D$ ” a internacionalização possibilita

Primeiro, a consolidação do IFCE, a marca IFCE. Se o IFCE pretende ser grande, ele necessariamente tem que ter um dos seus pilares a internacionalização. Um segundo ponto é a importância da internacionalização para os programas de pós-graduação e para a pesquisa e inovação na instituição - similarmente e de forma transversal isso atinge a extensão e o ensino. Você não pode distanciar esses dois nortes da pesquisa, da pós-graduação e da inovação. Esse é um segundo pilar. A importância é necessariamente para isso. (ENTREVISTADO D, 2018). 
Apesar disso, a mobilidade acadêmica ainda é mais intensamente destacada que as ações de pesquisa, tais como redes de pesquisa.

Outra razão apontada é o potencial cearense para atrair estrangeiros, seja pelo comércio, seja para riquezas naturais ou pela posição econômica. Essa atenção estrangeira torna-se umas das razões para que o IFCE busque parcerias externas e atraia interessados para a região. Isso pode ser explicado ainda pela história recente do IFCE em pesquisa, em que a visão estratégica de alianças com instituições de destaque e competitividade não é tão desenvolvido quando, por exemplo, se compara a UFC, em que se percebe um discurso mais alinhado com a busca pela reputação e prestígio internacional.

A busca por recursos financeiros e atração de estrangeiros para o Ceará foram outras razões citadas isoladamente pelos entrevistados.

$\mathrm{Na}$ UNILAB, os respondentes apontam diversas razões para a internacionalização. Tendo em vista que no próprio nome conste a palavra "internacional", não é surpresa que principal razão elencada pelos respondentes é a missão institucional associada à criação da UNILAB, uma necessidade nata da instituição, segundo o entrevistado "R", que também defende que a internacionalização é um processo irreversível, o quarto pilar da universidade. Consoante a isso, o entrevistado "S" enxerga a internacionalização como um imperativo do ambiente universitário:

\section{A universidade não pode parar no tempo, ela precisa ter esse olhar pensando da formação de pessoas do Brasil, mas direcionado para o contexto que o mundo está caminhando. As políticas de internacionalização estão direcionando e como nós vamos poder ampliar o escopo de ações que nós desenvolvemos em cada área, que nós temos ações de cursos de graduação e de pós-graduação. Mas não podemos ficar parados nesse contexto (ENTREVISTADO S, 2018).}

$\mathrm{Na}$ busca de cumprir sua missão, a UNILAB compreende que assim será uma universidade internacionalizada.

Diferente das instituições anteriores, os entrevistados da UNILAB ressaltaram a capacitação discente do estudante recepcionado. Isso ocorre pelo fato de a universidade ter como característica ocupar metade das vagas com estudantes de países africanos de Língua Portuguesa e Timor Leste. As atividades institucionais envolvem a promoção da universidade entre os países parceiros para atrair ingressantes estrangeiros, que recebem auxílio financeiro para residir no país.

As parcerias e alianças estratégicas com objetivo de troca de experiência e conhecimentos não foram exploradas pelos entrevistados, isso se deve possivelmente aos países que a UNILAB realiza as principais parcerias, que são justamente aqueles do contexto da 
cooperação solidária, onde o Brasil atua mais como um apoio e subsídio do que uma relação igualitária de trocas.

A internacionalização da UNILAB está relacionada à sua missão institucional, logo suas atividades cotidianas são norteadas naturalmente para o tema, assim, ao mesmo tempo em que orienta, estreita sua visão para a comunidade lusófona. Contudo, isso não significa que a instituição não possa fazer parcerias estratégicas com os países mais desenvolvidos, onde a internacionalização é mais intensa. Ressalta-se que há alunos da universidade em mobilidade acadêmica em países europeus.

O quadro 2 sintetiza as principais razões encontradas nos resultados.

Quadro 2 - Síntese das principais razões

\begin{tabular}{|c|c|}
\hline RAZÕES & AUTORES \\
\hline Capacitação de docentes & De Wit (2002); Knight (2004) \\
\hline Desenvolvimento cultural dos discentes & Warner (1992); De Wit (2002); Knight (2004) \\
\hline Desenvolvimento profissional dos discentes & De Wit (2002); Knight (2004) \\
\hline Parcerias & De Wit (2002); Knight (2004) \\
\hline Reputação & De Wit (2002); Knight (2004) \\
\hline Demandas externas/Pressões do Ambiente & Scott (1992); Knight (2004) \\
\hline
\end{tabular}

Fonte: Autores

\section{Considerações finais}

A internacionalização não é fenômeno recente no ensino superior, porém tem se intensificado especialmente nas últimas décadas. No Brasil, as universidades públicas lideram esse processo, evidenciado pelo protagonismo nas parcerias internacionais, publicações científicas e mobilidade acadêmica, dentre outros. O que é possível observar, no entanto, que no ensino superior a internacionalização ocorre por ações pontuais em vez de um processo com objetivos, metas e controle definidos.

De forma gradativa a internacionalização vem sendo institucionalizada, seja nas estruturas hierárquicas, seja nos instrumentos de planejamento como o Plano de Desenvolvimento Institucional. Diante disso, antes de avançar nos aspectos gerenciais 
envolvidos, é essencial refletir os motivos pelos quais as IES aderem/devem aderir ao processo de internacionalização.

A pesquisa desenvolveu-se nas instituições federais de ensino superior no Ceará. $\mathrm{O}$ recorte de instituições federais permitiu comparabilidade, visto que elas se submetem à mesma estrutura hierárquica, legislação, disputa de recursos e outras semelhanças, embora se diferenciem em sua trajetória.

Os resultados indicaram que as instituições buscam a internacionalização sobretudo como meio de atingir outros objetivos institucionais. Primeiro, a internacionalização viabiliza capacitação docente com pesquisadores internacionais, que eleva o nível de qualidade da pesquisa da IES, que por sua vez leva à visibilidade (reputação) da instituição. Esse ponto é mais fortemente observado na UFC, que pode ser entendido ao se compreender seu pioneirismo em ações de internacionalização e a presença massiva de cursos de pós-graduação, que se constitui uma das pontes mais eminentes para universidades do exterior.

Além das questões institucionais, o desenvolvimento cultural e cidadão dos estudantes foi bastante citado e representa uma importante descoberta do estudo. A compreensão da internacionalização universitária em uma perspectiva cidadã por vezes é esquecida por grandes universidades, mais atentas à reputação e ao impacto da comunidade científica.

A irreversibilidade da internacionalização no ensino superior é demonstrada pelas demandas advindas do ambiente universitário. Nesse aspecto, destacam-se ações governamentais de fomento, como o Programa Ciências sem Fronteiras, na graduação, e o Programa Institucional de Internacionalização (PrInt), na pós-graduação. Pressões são advindas de exigências dos órgãos reguladores para estabelecimento e consecução de objetivos de internacionalização ou de instituições estrangeiras.

A UNILAB apresentou particularidades devido à sua missão institucional. Ao mesmo tempo que suas atividades são diretamente vinculadas ao internacional, seu foco em países de Língua Portuguesa torna sua atuação distante da região onde a internacionalização é mais intensa (Europa e Estados Unidos).

No geral, as razões que levam as instituições federais de ensino superior do Ceará a aderir ao processo de internacionalização são convergentes com a literatura pesquisada. Diferenças podem ser justificadas pelo processo histórico e pela estrutura que cada instituição desenvolveu, que resulta em diferentes estágios de internacionalização, onde a UFC encontrase mais aderida às demandas internacionais.

A escolha dos entrevistados constitui-se umas das limitações da pesquisa. Ao buscar as razões institucionais da internacionalização, a pesquisa concentrou-se nos gestores da 
Administração Superior, não abrangendo os grupos essenciais que são produtos do processo: os professores e os estudantes. De forma semelhante, a seleção de instituições federais exclui a possível contribuição das universidades estaduais. À medida que a pesquisa possui limitações, essas convertem-se em sugestões para estudos posteriores.

\section{Referências}

AIGNER, Jean; NELSON, Patricia; STIMPFL, Joseph. R. Internationalizaling the University: make it work. Springfield: CBIS Federal, 1992.

ALTBACH, Philip. G. Globalization and the university: myths and realities in a inequal world. Tertiary Education and Management, Amsterdam, n. 1, p. 3-25, Mar. 2004. Disponível em: DOI: 10.1023/B:TEAM.0000012239.55136.4b.

ALTBACH, Philip. G.; KNIGHT, Jane. The internationalization of higher education: motivations e realities. Journal of Studies in International Education, California, v. 11, n. 3/4, p. 290-305, 2007. Disponível em: https://doi.org/10.1177/1028315307303542.

BATISTA, Janaína Siegler Marques. O processo de internacionalização das instituições de ensino superior: um estudo de caso na Universidade Federal de Uberlândia. 2009. Dissertação (Mestrado em Administração de Organizações) - Faculdade de Economia, Administração e Contabilidade de Ribeirão Preto, Universidade de São Paulo, Ribeirão Preto, 2009.

BERRY, Caroline; TAYLOR, John. Internationalisation in higher education in Latin America: policies and practice in Colombia and Mexico. Higher Education, Amsterdam, v. 67, n. 5, p. 585-601, 2014. Disponível em: https://doi.org/10.1007/s10734-013-9667-z.

BEZERRA, Maria das Graças Dantas. O processo de internacionalização da educação como fator estratégico de desenvolvimento institucional. 2012. Dissertação (Mestrado Profissional em Administração) - Universidade Potiguar, Natal, 2012.

CHRISTINO, Adriana Maria. Internacionalização de ensino superior: estudo de caso em cursos de Administração de instituições públicas de ensino superior. 2013. Dissertação (Mestrado em Administração de Organizações) - Universidade de São Paulo, Ribeirão Preto, 2013.

DENZIN, Norman K.; LINCOLN, Yvonna S. Collecting and interpreting qualitative materials. 2. ed. California: Sage Publications, 2003.

DE WIT, Hans. Changings rationales for the internationalization of higher education. In: INTERNATIONALIZATION of higher education: an institutional perspective. Bucharest, Romania: UNESCO, 2000.

DE WIT, Hans. Internationalization of higher education in the United States of American and Europe: a historical, comparative and conceptual analysis. Westport: Greenwood Press, 2002.

DE WIT, Hans; ADAMS, Tony. Policies, rationales, and practices in Australia and Europe. In: PORTNOI, L. M.; BAGLEY, S. S.; RUST, V. D. (ed.). Higher education, policy, and the global competition phenomenon. New York: Palgrave Macmillan, 2010. p. 219-233.

DE WIT, Hans. Internationalization in higher education, a critical review. SFU Ed. Review, Burnaby, v. 12, n. 3, p. 9-17, 2019. Disponível em: https://doi.org/10.21810/sfuer.v12i3.1036. 
GAO, Yuan; BAIK, Chi; ARKOUDIS, Sophia. Internationalization of Higher Education. In: HUISMAN, J.; DE BOER, J.; DILL, D.D.; SOUTO OTERO, M. (ed.). The palgrave international handbook of higher education policy and governance. London: Palgrave Macmillan, 2015. p. 300-320.

GODOI, Cristiane Kleinubing; MATTOS, Pedro Lincoln.C.L. Entrevista qualitativa: instrumento de pesquisa e evento dialógico. In: SILVA, A.B.; GODOI, C.K.; BANDEIRADE-MELLO, R. Pesquisa qualitativa em estudos organizacionais: paradigmas, estratégias e métodos. São Paulo: Saraiva, 2006. p. 300-320.

HUDSON, Ross. Dominated by economics? Evidence of changing drivers of internationalization and Its Funding Within Higher Education Institutions in Europe. Higher Education Policy, California, v. 29, p. 1-19, 2016. Disponível em: https://doi.org/10.1057/hep.2015.4.

IFCE - INSTITUTO FEDERAL DO CEARÁ. Institucional. Fortaleza: IFCE, 2015. Disponível em: https://ifce.edu.br/acesso-a-informacao/Institucional. Acesso em: 12 abr. 2020.

IFCE - INSTITUTO FEDERAL DO CEARÁ. Pró Reitoria de Administração e Planejamento. Anuário Estatístico 2017 Ano Base 2016. Fortaleza: IFCE, 2017.

KNIGHT, Jane. Updated internationalization definition. International Higher Education, Boston, v. 33, p. 2-3, 2003. Disponível em: https://doi.org/10.6017/ihe.2003.33.7391.

KNIGHT, Jane. Internationalization remodeled: definitions, approaches, and rationales. Journal of Studies in International Education, Califórnia, v. 8, n. 5, p. 4-31, 2004. Disponível em: https://doi.org/10.1177/1028315303260832.

KNIGHT, Jane. An internationalization model: responding to new realities and challenges. In: DE WIT, H.; JARAMILLO, I. C.; GACEL-AVILA, J.; KNIGHT, J. (ed.).

Internationalization of higher education in Latin America: the international dimension. Washington DC: World Bank, 2005. p. 1-38.

KNIGHT, Jane. Student mobility and internationalization: trends and tribulations. Research in Comparative and International Education, Califórnia v. 7, n. 1, p. 20-33, 2012. Disponível em: https://doi.org/10.2304/rcie.2012.7.1.20.

LAUS, Sonia Pereira. A internacionalização da educação superior: um estudo de caso na Universidade Federal de Santa Catarina. 2012. Tese (Doutorado) - Núcleo de Pós-Graduação em Administração, Universidade Federal da Bahia, Salvador, 2012.

MIURA, Irene Kazumi. O processo de internacionalização da Universidade de São Paulo: um estudo de três áreas de conhecimento. 2006. Tese (Livre Docência) - Faculdade de Economia, Administração e Contabilidade de Ribeirão Preto, Universidade de São Paulo, Ribeirão Preto, 2006.

MORGADO, José Carlos. Processo de Bolonha e Ensino Superior num mundo globalizado. Educação \& Sociedade, Campinas, v. 30, n. 106, p. 37-62, jan./abr. 2009. Disponível em: https://doi.org/10.1590/S0101-73302009000100003.

MUELLER, Cristiana Verônica. O processo de internacionalização do ensino superior: um estudo de caso na Universidade Federal do Rio Grande do Sul. 2013. Dissertação (Mestrado em Relações Internacionais) - Universidade Federal do Rio Grande do Sul, Porto Alegre, 2013. 
NEZ, Egeslaine. Fluxos de cooperação acadêmica para a internacionalização. In: MOROSINI, M. (org.). Guia para a internacionalização universitária. Porto Alegre: PUCRS, 2019. p. 151-166.

OLIVEIRA, Paula Souza de. Internacionalização da educação superior: um estudo de caso em instituições públicas de ensino superior no Estado da Bahia. 2018. Dissertação (Mestrado em Educação) - Universidade Federal da Bahia, Salvador, 2018.

SEEBER, Marco et al. Why do Higher Education Institutions Internationalize? An investigations of the multilevel determinants of internationalization rationales. Higher Education, Amsterdam, v. 8, p. 685-702, 2016. Disponível em: https://doi.org/10.1007/s10734-015-9971-x.

SEEBER, Marco; MEOLI, Michele; CATTANEO, Mattia. How do European Higher Education Institutions Internationalize? Studies in Higher Education, London, v. 45, n. 1, p. 145-162, 2018. Disponível em: https://doi.org/10.1080/03075079.2018.1541449

SCOTT, Robert A. Campus developments in response to the challenges of internationalization: the case of Ramapo College of New Jersey (USA). Springfield: CBIS Federal, 1992.

TEICHLER, Ulrich. Internationalisation of higher education: European experiences. Asia Pacific Education Review, Seoul, v. 10, n. 1, p. 93-96, 2009. Disponível em: https://doi.org/10.1007/s12564-009-9002-7.

UNILAB - UNIVERSIDADE DA INTEGRAÇÃO INTERNACIONAL DA LUSOFONIA AFRO-BRASILEIRA. UNILAB: caminhos e desafios acadêmicos da Cooperação Sul-Sul. Redenção: UNILAB, 2013.

UNILAB - UNIVERSIDADE DA INTEGRAÇÃO INTERNACIONAL DA LUSOFONIA AFRO-BRASILEIRA. UNILAB: como surgiu. Redenção: UNILAB, 2018a. Disponível em: http://www.unilab.edu.br/como-surgiu/. Acesso em: 21 ago. 2018.

UNILAB - UNIVERSIDADE DA INTEGRAÇÃO INTERNACIONAL DA LUSOFONIA AFRO-BRASILEIRA. Relatório de Gestão 2017. Redenção: UNILAB, 2018b. Disponível em: http://www.unilab.edu.br/wp-content/uploads/2018/05/Relat\%C3\%B3rio-Gerencial2017.pdf. Acesso em: 18 set. 2018.

UNILAB - UNIVERSIDADE DA INTEGRAÇÃO INTERNACIONAL DA LUSOFONIA AFRO-BRASILEIRA. Guia do Estudante da UNILAB. Redenção: UNILAB, 2018c. Disponível em: https://drive.google.com/file/d/0B_ozBePkZTDxaUNyeFlKNUJSM2c/view. Acesso em: 18 set. 2018.

UNILAB - UNIVERSIDADE DA INTEGRAÇÃO INTERNACIONAL DA LUSOFONIA AFRO-BRASILEIRA.UNILAB em números. Redenção: UNILAB, 2018d. Disponível em: https://unilab.edu.br/unilab-em-numeros/. Acesso em: 18 set. 2018.

UFC - UNIVERSIDADE FEDERAL DO CEARÁ. Coordenadores de Programas de PósGraduação comemoram ótima avaliação da CAPES. Coordenadoria de Comunicação e Marketing Institucional. Fortaleza, 2017. Disponível em: http://www.ufc.br/noticias/noticias-de-2017/10236-coordenadores-de-programas-de-posgraduacao-comemoram-otima-avaliacao-da-capes. Acesso em: 12 dez. 2017.

UFC - UNIVERSIDADE FEDERAL DO CEARÁ. Plano de Internacionalização. Conselho Universitário. Fortaleza, 2018a. Disponível em: http://www.ufc.br/images/_files/a_universidade/plano-internacionalizacao-ufc/planointernacionalizacao-ufc.pdf. Acesso em: 17 set. 2018. 
UFC - UNIVERSIDADE FEDERAL DO CEARÁ. Criação do Comitê de Governança. Conselho Universitário. Fortaleza, 2018b. Disponível em:

http://www.secretariadegovernanca.ufc.br/resolucao-012017-do-consuni/. Acesso em: 18 set. 2018.

UFC - UNIVERSIDADE FEDERAL DO CEARÁ. Pró-Reitoria de Relações Internacionais. Sobre a PROINTER. Fortaleza, 2018c. Disponível em: http://www.prointer.ufc.br/pt/sobrea-prointer/. Acesso em: 20 set. 2018.

VILALTA, Luis Antônio. A internacionalização do ensino superior brasileiro: conceitos e características do processo em instituições privadas de ensino superior. 2012. Tese (Doutorado em Educação) - Pontifícia Universidade Católica, São Paulo, 2012.

WADWHA, Rashim. New phase of internationalization of higher education and institutional change. Higher Education for the Future, New York, v. 3, n. 2, p. 227-246, 2016.

Disponível em: https://doi.org/10.1177/2347631116650548.

WARNER, Gary. Internationalization models and the role of the university. International Education Magazine, Califórnia, p. 21, 1992. 